\title{
Estimates of Disability Among Ethnic Groups in Hawaii
}

\author{
Ann M. Pobutsky, Robert Hirokawa, and Florentina Reyes-Salvail
}

Hawaii State Department of Health

\begin{abstract}
Objective: To estimate and describe the current prevalence of disability among Hawaii's population. Design, Setting, and Participants: Random-digit telephone survey of 6,000 adults aged 18 and older residing in Hawaii and participating in the Behavioral Risk Factor Surveillance System in 2002 and the 2000 US Census. Main Outcome Measures: Any disability, indicators of disability severity by ethnicity, age, and gender. Results: Filipinos and Native Hawaiians are experiencing higher age-specific levels of disability when compared with their Japanese and White counterparts. Within the working-aged population, Native Hawaiians experience a more severe level of disability than other ethnic groups. Within the elderly population, it appears that Filipinos experience a more severe level of disability. One third of Native Hawaiians attribute their disability to the effects of a stroke, one third of Filipinos attribute their disability to the effects of heart disease, and one fourth to one third of Whites and Japanese who attribute their disability to arthritis. Conclusions: We have described the current prevalence of disability among Hawaii's population based on two established population-based surveillance systems: The US Census and the Behavioral Risk Factor Surveillance System. Preliminary findings suggest that Native Hawaiians and Filipinos may be experiencing more severe levels of disability. The data also suggests that disability among Native Hawaiians and Filipinos may be associated with stroke and heart disease. More information is needed about disability and health among ethnic groups in Hawaii and the Pacific region. Population aging in Hawaii, as well as the increase in non-communicable diseases will result in larger numbers of people with disabilities who will need health and other services.
\end{abstract}

(C) 2003 Californian Journal of Health Promotion. All rights reserved.

Keywords: disability, chronic disease, ethnicity, Hawaii

\section{Introduction}

Surveillance of disability, chronic diseases and their associated co-morbidities has become necessary in order to provide information about this growing segment of the population. Disability affects at least 1 in 5 people in the U.S., many with severe loss of function. Disability rates vary by age, sex and ethnicity and is associated with poverty and additional health problems. While disability is a major public health problem in the U.S. (Lollar, 2002), not much is known about disability rates among Pacific Islanders. In the U.S., Pacific islanders are often combined with Asians when research is compiled on population health indicators. As a result, their health status is obscured because, in general, Asians tend to have lower rates of disease and disability compared to other ethnic groups in the U.S. Hawaii is also one of many states that has a large and growing proportion of elderly persons; examining age-related disability among Hawaii's diverse ethnic population will provide information for health planning and policies addressing the needs of people with disabilities and chronic conditions.

In Hawaii, it is known that the prevalence of many chronic conditions varies by ethnic group, and there has been some available data on selfidentified activity limitations, the most commonly used proximate measure of disability. However, little has been done to examine ethnic differences in disability because of limited data on the topic. Utilizing the most recent 2000 U.S. Census data, along with recent data from the Hawaii State Department of Health's 2002 
Behavioral Risk Factor Surveillance Survey, disability prevalence estimates are summarized for different ethnic groups in order to examine likely differentials. Findings reveal that severe disabilities disproportionately affect Native Hawaiians and Filipinos in Hawaii.

\section{Disability: Definitional and Measurement Issues}

What defines disability is a complicated issue, which further complicates how disability is measured. One problem with measuring conditions such as disability and illness is “...not knowing how to count different things...if we use pain or disability as a common denominator, how much pain or disability assessed by whom and how often? (Wilkinson, 1996, p. 55)."

Within the field of public health, the most recent model of disablement focuses on disability “...not as a human attribute that demarks one portion of humanity from another (as gender does, and race sometimes does); rather, it is an infinitely various but universal feature of the human condition (Bickenbach et. al., 1999, p. 1182)." This conception of disability has evolved as a result of a move away from a purely bio-medical and rehabilitation model of disability, which defines disability in terms of an attributes of a person, to a focus on aspects of the social and physical environment which are disabling.

Having a disability is not a fixed status, but rather a continually changing, evolving, and interactive process. It is not something that one is or not, but instead is a set of characteristics everyone shares to varying degrees and in varying forms and combinations. This does not mean that disability is unmeasureable. Instead its conception, measurement, and counting differs validly with the purposes for which such numbers are used (Zola, 1993).

Clearly there is a medical and health component to disablement, yet the socio-political changes that have developed as a result of activism have pointed to the obstacles of the social and physical environment which prevent people with disabilities from fully participating in the community. Activists and people with disabilities have used a minority group and civil rights perspective to have legal solutions to discrimination and gain access to needed services and the physical environment. Yet, while this has paved the way for numerous social changes and policies, people with disabilities are not a "...homogeneous group with a unifying culture, language or set of experiences (Bickenbach et al, 1999:1181)" and most of the problems people with disabilities face are not forms of discrimination but rather “...social ills brought about by unfair distribution of societies resources and opportunities that results in limitations of participation in all areas of life (Bickenbach et al, 1999, p. 1181)." Such systemic and institutional distributional injustice persists because of the "...variation in impairmentrelated needs and disability accommodations. In the case of physical disabilities, the higher the level of impairment need, the smaller the population cohort, with the result that more common impairment needs (such as glasses for mild visual impairment) tend to be catered to, while more complex and less common needs (say those for spina bifida) are more likely to be underserved (Bickenbach et al., 1999, p. 1181).” Thus, what constitutes a disability or what (or who) is counted, has socio-political ramifications.

The issues of disability as a departure from medical or social acceptable "norms", the historical or "moral" model of disability as punishment, and the issues of stigma and shame are not the focus of this paper. Such factors are salient today and deserve a more detailed and thorough examination with regard to how these can influence measurement of diseases or conditions. The treatment of people with Hanson's disease in Hawaii and those with amyotrophic lateral sclerosis and parkinsonismdementia (ALS-PD) on Guam would be good examples (Pobutsky-Workman, \& KammingaQuinata, 1996; Robello Breitha, 1991).

The most recent focus on disability as a universal human condition is reflected in the World Health Organizations' ICF- International Classification of Functioning, Disability and Health (WHO, 2001), whereby "disability serves 
as an umbrella term for impairments, activity limitations or participation restrictions”. This new focus is leading to ways of measuring aspects of the environment which are disabling, which are finding their way into health surveys such as the Behavioral Risk Factor Surveillance Survey (CDC, 2002). The Behavioral Risk Factor Surveillance System (BRFSS) is an annual telephone survey of non-institutionalized adults ( $>18$ years) in the United State which has been conducted in all the states and territories since 1988. The BRFSS assesses risk factors for disease(s) and conditions related to the ten leading causes of death in the U.S. population, and while 16 states now collect detailed data on disabilities and social-environmental variables, all states can utilize the quality of life module questions to examine the overall prevalence of disabilities, based on a number of definitions.

Keeping these definitional issues in mind, there are still reasonable ways to measure disabilities and assess the prevalence of disabilities in populations. There is no exact number for overall prevalence of disabilities since (1) prevalence of disabilities depends on how disabilities are defined by agencies or organizations which gather data and generate statistics, and (2) prevalence rates will change over time (Kaye, LaPlante, Carlson \& Wenger, 1996). However, general patterns can be discerned from available data to provide a reasonable prevalence range, using various definitions of disability. According to Mitchell LaPlante of the Disability Statistics Center, there are two main ways to define disability: One is by looking at how people function-basic things humans can do. The other one is activities-the things we do in going about our daily lives, the activities we have difficulty doing, or have limitations in. And these are separate things. And when we try to measure these things, we come up with different estimates of what disability is (LaPlante, 2003).

Don Lollar of the Center's for Disease Control points out that: "Disability is a demographic variable---just like age, sex, racial ethnicity, socio-economic status - and it needs to be seen that way, as opposed to a negative health outcome....Disability is a way of identifying another risk factor that contributes to lessened participation in common activities like going to school, working, voting, participating in community life (Lollar cited in http://www.accessiblesociety.org).”

The BRFSS uses "activity limitations" as one self-identifier for disability, along with use of special equipment, and ADL/IADL limitations (activities of daily living and instrumental activities of daily living). In addition, the BRFSS examines health status, social participation and secondary conditions relative to disability status. The US Census also assesses a number of self-reported physical, mental, functional and activity limitations.

\section{U.S. Patterns of Disability and the Prevalence of Chronic Conditions}

It is estimated that one-half of people with disabilities "...have disabilities caused by or related to the aging process (Ellis, 1997).” The most common set of indicators for disabilities are chronic conditions, which provide the highest prevalence estimates (Zola, 1993). The 2000 US Census collected data about disabilities for the working age population (persons aged 16-64) and for the elderly (persons aged 65 and older), for all States as well as nationally. Using a definition of disability based on self-reports of difficulties in various functional tasks (seeing, hearing, or getting around), the 2000 US Census generated a number of about 49 million people with disabilities. The US Census Survey of Income and Program Participation (SIPP) generated larger estimates of 54 million people with disabilities in the late 1990's. The problem is that these estimates (and any survey estimates) do not include institutionalized elderly people or mental health disabilities not involving cognitive impairments, so the numbers are likely much higher.

Ethnic differentials in disabilities in Hawaii will be explored after some of the general relationships between disability and other health-related indictors are summarized and U.S. patterns of disability are described.

Disability rates differ by age, sex, race/ethnicity and income. Rates are higher for older people and women; women's longer life expectancy 
“...means that women make up a large share of older persons with a disability $(65.2 \%$ of persons 65 years old and over with a severe disability are women)(McNeil, 1997)." Disability is associated with lower income levels and poverty, a reduced chance for employment, and an increased likelihood of having health insurance from the Federal Government (Medicare/Medicaid). Disability also varies by race/ethnicity, with the highest rates among American Indians, Eskimos, Aleuts and Blacks and the lowest among Asians and Pacific Islanders. However, in U.S. mainland surveys, Pacific islanders are often combined with Asians when research is compiled on population health indicators. As a result, their health status is obscured because, in general, Asians tend to have the lower rates of disease and disability compared to other ethnic groups in the U.S.

Chronic diseases and subsequent death rates are keys to patterns of disabilities. The ten leading causes of death in the U.S. in 1995 were cardiovascular diseases, cancer, unintentional injuries, chronic obstructive pulmonary disease, pneumonia and influenza, diabetes mellitus, HIV, suicide, homicide and other causes. However, deaths due to four chronic diseases (cardiovascular diseases, cancers, chronic obstructive pulmonary disease and diabetes) accounted for $71.6 \%$ of all deaths in the U.S. in 1995 (CDC, 1998). The culprits for the leading causes of death in the U.S. are tobacco, poor diet and in-activity, alcohol, microbes (including preventable infections), known exposure to toxic agents, firearms, sexual behavior (mainly HIV), motor vehicles (not including alcohol related crashes) and illicit drugs (mainly due to HIV and hepatitis B) (McGinnis \& Foege, 1993). Of these in 1993, tobacco, poor diet/in-activity account for $37.7 \%$ and $28.3 \%$ respectively or two-thirds of all annual deaths (McGinnis \& Foege, 1993). McGinnis and Foege point out that these indicators not only "...contribute to deaths, those deaths are by definition premature and are often preceded by impaired quality of life (McGinnis \& Foege, 1993, p. 2207)”.

Overall, disability tends to be associated with chronic disease and aging. The top ten chronic conditions that cause activity limitations are: heart disease, back problems, arthritis, asthma, diabetes, mental disorders, eye disorders, learning disabilities/mental retardation, cancer and visual impairments (Kraus et al; 1996:26). The top ten most frequently limiting conditions are: mental retardation, multiple sclerosis, cancers of the stomach, intestine, colon and rectum, paralysis of extremities, cancers of the lungs or respiratory tracts, blindness, orthopedic impairments, other paralysis, diseases of the heart (not including hypertension) and epilepsy (Kraus et al; 1996). Of the above, heart disease, back disorders, arthritis, lower extremity orthopedic disorders and asthma, account for three-quarters of the disabilities among people with disabilities (Ellis, 1997).

Ellis points out that "the concept of disability as a function of the aging process is largely foreign to today's disability community (Ellis, 1997, p. 12)." Due to the large proportion of elderly persons in Hawaii we could expect disability patterns to follow the U.S. pattern, yet it is likely that ethnicity is associated with higher rates of disability in Hawaii because there are known ethnic differences in morbidity and mortality (Hawaii State Department of Health, 2003). We do know that Native Americans and other minority groups throughout the U.S. have differential mortality rates than Whites, thus disabilities are also more prevalent. Overall, Hawaii has slightly lower chronic disease and mortality rates than the U.S. as a whole, but Native Hawaiians and other Pacific Islanders have the worst health in Hawaii compared to other ethnic groups (CDC, 2002; Kekuni Blaisdell, 1993). For example, Native Hawaiians have death rates 4 times higher than all other ethnic groups combined, as well as high rates of chronic diseases and debilitating conditions such as cancer, diabetes and heart disease (Centers for Disease Control, 2002).

The importance of such ethnic differences is necessary not only to understand why differences are apparent relative to the prevalence of diseases or conditions, but also to figure out preventive strategies. This paper focuses on ethnic differences because ethnicity is a definitive way to examine health disparities: 
Race and ethnicity are not risk factors -- they are markers used to better understand risk factors. ...Further, there should be further exploration of the full utility of the concept of ethnicity. This term generally has been limited to definers such as surname or language, while ignoring, for example, the importance of historical and sociological experiences (CDC, 1993).

\section{Patterns of Work Disabilities Among Persons Aged 16-64 in the U.S.}

Based on information from the Survey of Income and Program Participation (SIPP), about “...32 million working age people (or $18.7 \%$ of the population age 15 to 64) have a work disability (Stoddard et. al.,1998).” The main chronic conditions causing work limitation are back disorders, followed by heart disease, arthritis, respiratory diseases, mental disorders, lower extremity impairments and diabetes (Stoddard et. al., 1998). Employment is lowest among people with mobility impairments and yet almost $80 \%$ of people with disabilities of working age would like to work (Stoddard et. al., 1998). While men and women have similar rates of work disability, minorities have the highest rates of work limitation; and both work disability and severe work disability generally increase with age. While the incidence rate of occupational injuries and illnesses has decreased, the effect has increased (lost work days per 100 workers) from 1972 to 1991 (Stoddard et. al., 1998).

When examining work disability rates from Census data, LaPlante (1993) ranked the fifty states, Hawaii's work disability rates were quite low, with Hawaii ranking number 50 in 1980 and 49 in 1990 overall work disability (see LaPlante, 1993).

\section{Estimates of Disability Prevalence Among Ethnic Groups in Hawaii US Census 2000}

The 2000 US Census provided race/ethnic categories which included self-reported ethnicity "alone or in combination with one or more races". The data presented here include those who reported one ethnicity, so that "Native Hawaiian alone" does not include those who are of mixed ethnicity. Instead, those of mixed ethnicity are included under "two or more races alone” category. Note that these US Census figures are for the civilian, non-institutionalized population over 5 years of age. The 4 largest ethnic populations in Hawaii, based on "race alone" or "race alone or in combination" in the 2002 US Census were "Whites", Japanese, Filipinos, and Native Hawaiians. Other ethnic groups include: Chinese, Koreans and other Asians, and Samoans, Micronesians and other Pacific Islanders, and other ethnic groups http://www.hawaii.edu/dbedt/.

Using US Census data, a preliminary look at the proportions of people with any disability by age shows a general pattern of higher proportions among older age groups (Figure 1). Hawaii has rates that are slightly lower than other states and territories in the U.S. These differences in disability rates throughout the U.S. reflect different demographic characteristics of the particular state. States in the West tend to have higher rates due to aging populations, while states with high proportions of those in poverty also tend to have higher rates.

In Hawaii, the proportion of those with any disability is slightly lower for Whites and slightly higher for Asians (Figure 2a). Those of mixed ethnicities have the lowest rates. Recently released data from the US Census Summary File 4 allowed for a more detailed breakdown by ethnicity, illustrating that Filipinos have the highest proportions with any disability, followed by Japanese (Figure 2b).

A detailed breakdown by age reveals that Native Hawaiians, Filipinos and those of mixed ethnicities have higher age-specific disability rates than Japanese or Whites, at all ages (Figure 3). 


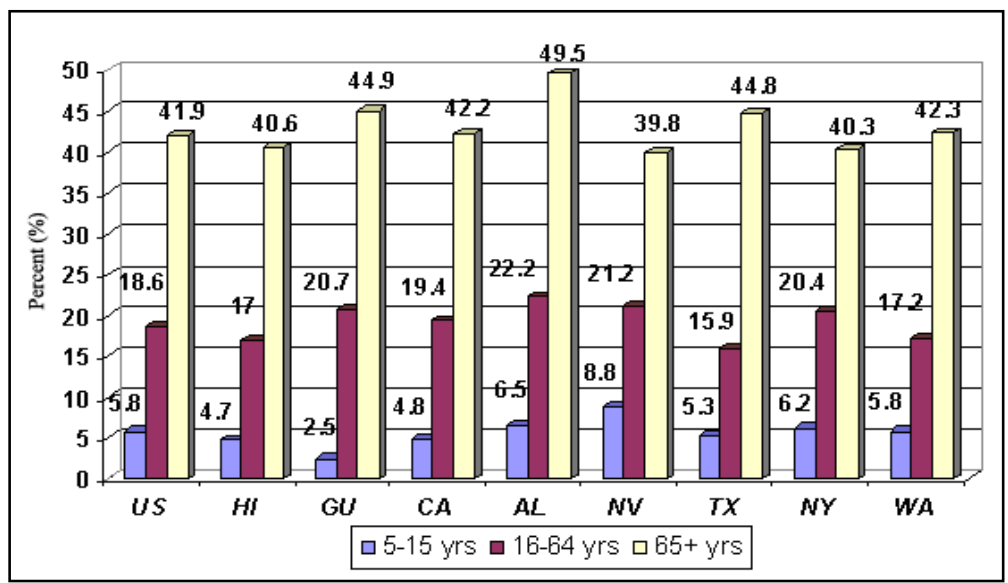

Figure 1

Disability by Age Among Persons $>5$ Years in Selected States and Territories, 2000 US Census

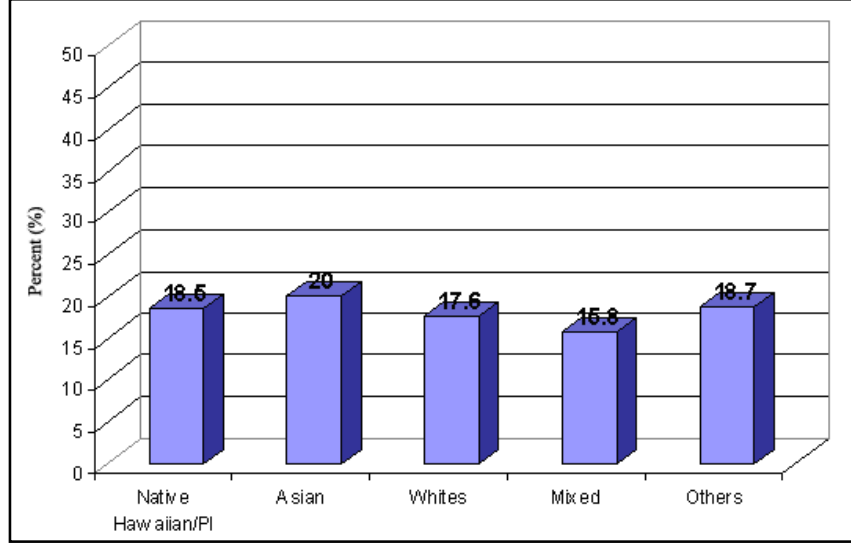

Figure 2a

Any Disability by Ethnicity (Alone) in Hawaii, 2000 US Census (Summary File 3)

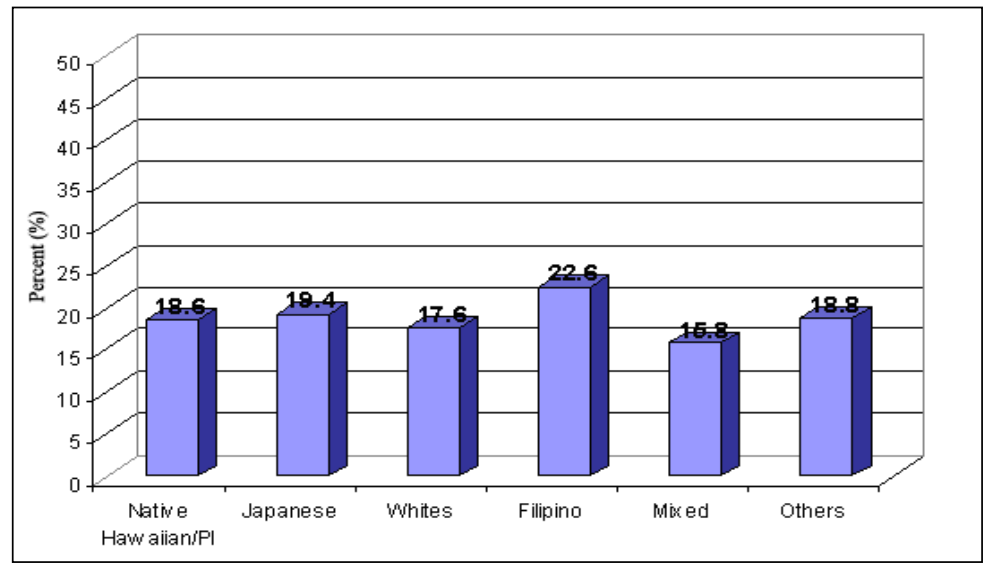

Figure $2 b$

Any Disability by Ethnicity (Alone) in Hawaii, 2000 US Census (Summary File 4) 


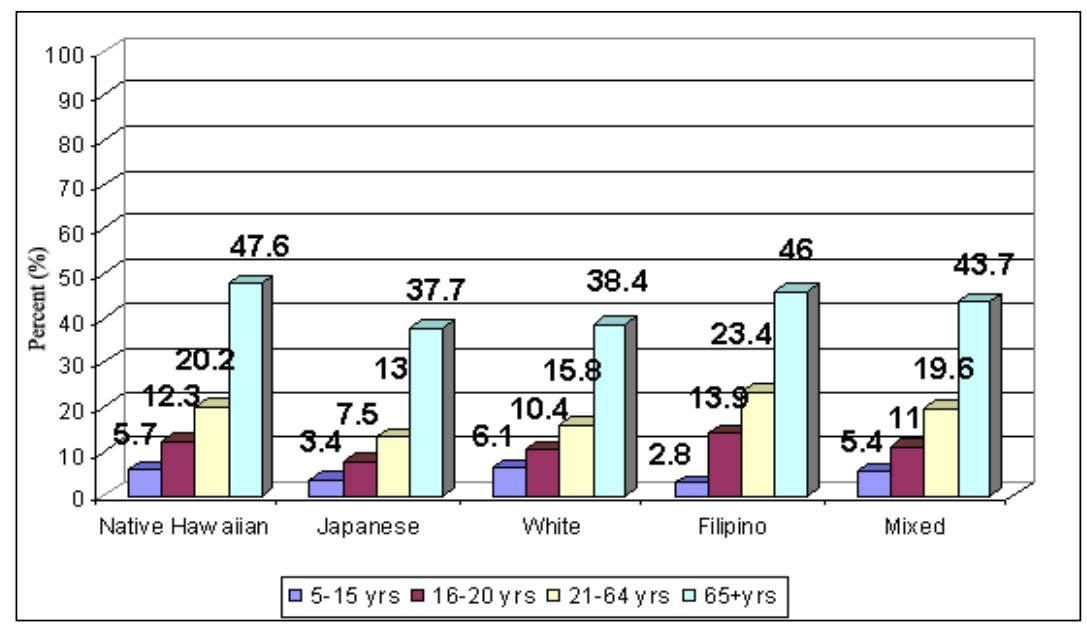

Figure 3

Disability by Age and Ethnicity (Alone), Hawaii, 2000 US Census

Rates are similar for males and females, yet at older ages, men are more likely to report disabilities than women in Hawaii (Figure 4). This is different from the US trend, where women are more likely to be disabled at older ages, and likely reflects Hawaii's aging cohort of single male plantation workers (Figures $5 \&$ $6)$.

At younger ages, for those reporting one disability, disabilities are more likely to be "mental disabilities" (which can include developmental disabilities and learning disabilities), and these are more common among Whites, Japanese, Native Hawaiians and those of mixed ethnicity for those ages 5-20 years in Hawaii (Figure 7). Filipinos have higher rates of a variety of disabilities within this age grouping, and also report the highest employment related disabilities (because this age grouping includes those up to age 20), as do the Japanese.

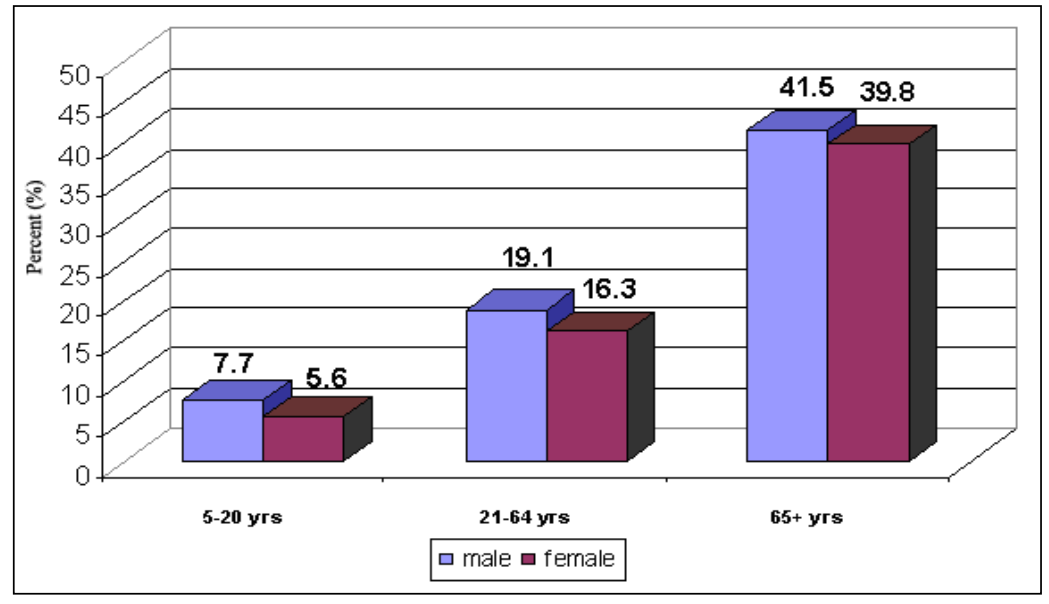

Figure 4

Disability by Sex and Age Group Among Persons >5 Years in Hawaii, 2000 US Census 


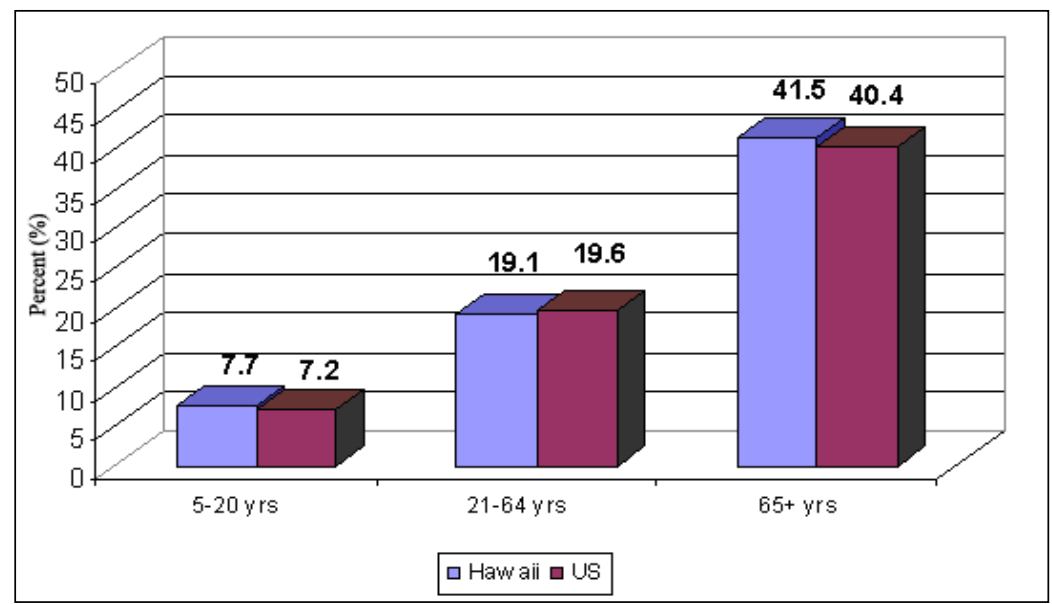

Figure 5

Disability by Age Group Among Males >5 Years in Hawaii and the US, 2000 Census

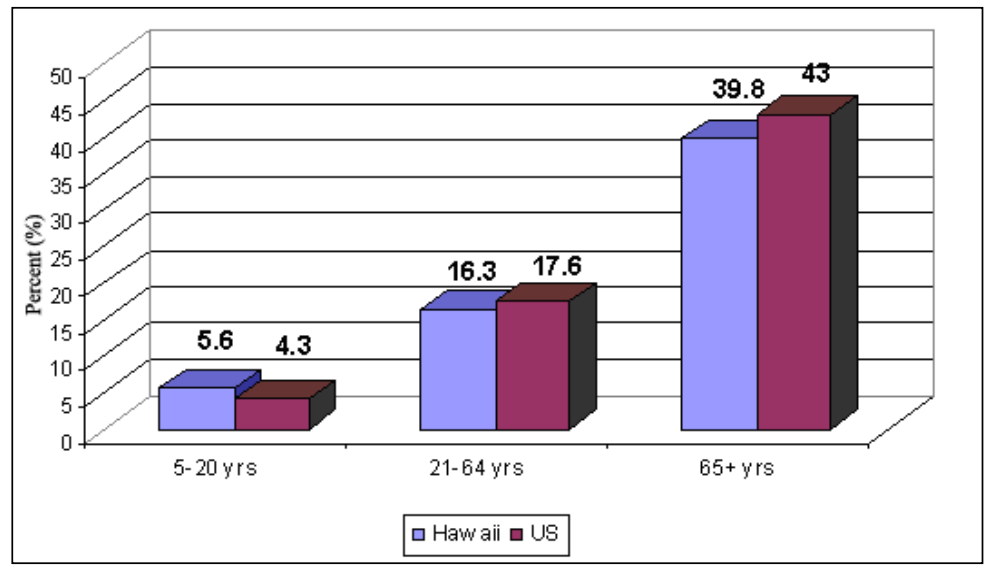

Figure 6

Disability by Age Group Among Females $>5$ Years in Hawaii and the US, 2000 US Census

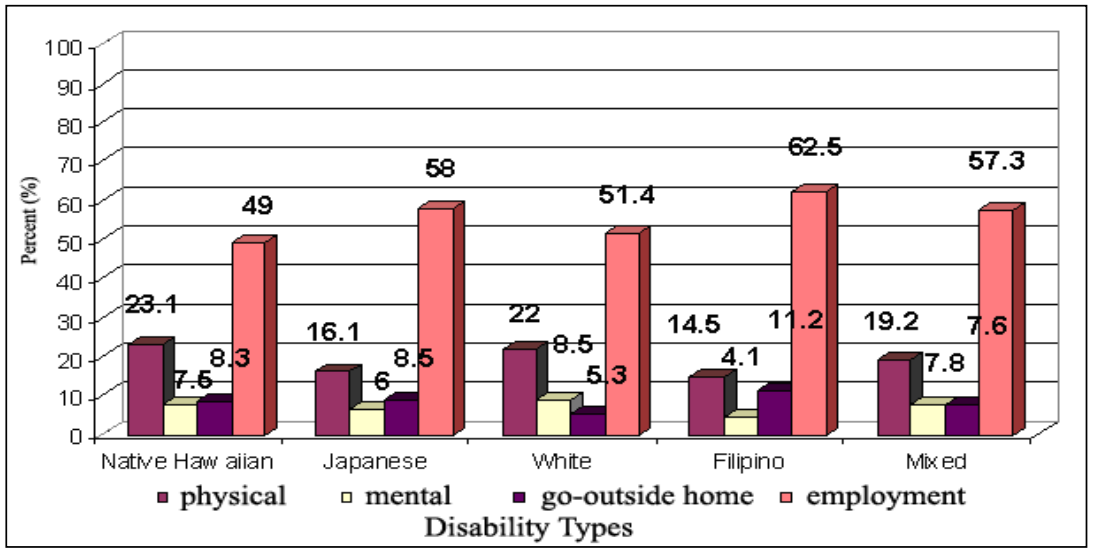

Figure 7

With One Type of Disability for Persons Ages 5-20 Years in Hawaii, 2000 Census 
Within the working age population, among those with one disability, one-half (50\% or more) are "employment disabilities" (probably occupational injuries) (Figure 8), with Filipinos again reporting the highest proportions, followed by Japanese and those of mixed ethnicity.

At older ages, among those with one disability, the two most common forms of disabilities are physical disabilities and "go outside home disabilities" (mobility problems) (Figure 9). Physical disabilities were slightly more prevalent among Whites (48.2\%) and Native Hawaiians (41.7\%), while "go outside home disabilities" was highest among Filipinos (50\%), followed by Japanese (37.9\%).

People who are older are also more likely to have more than one disability. Figure 10 depicts the proportions of elderly persons who have no, one or two disabilities. Native Hawaiians and Filipinos have the highest proportions reporting one or two disabilities, followed by those of mixed ethnicities.

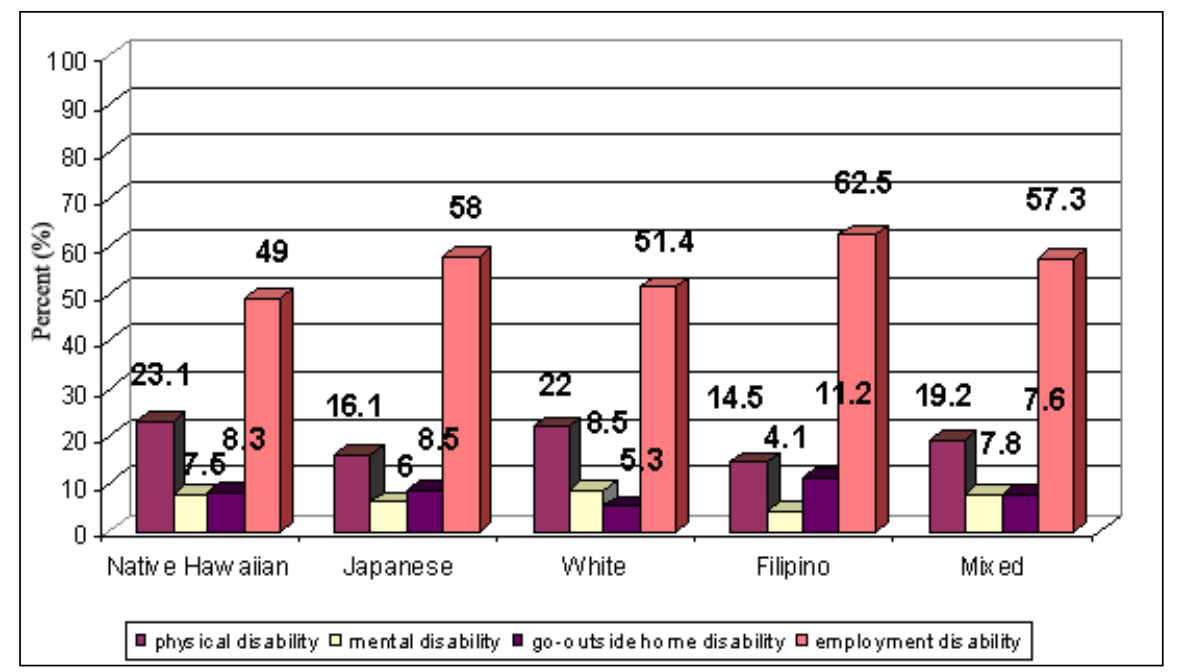

Figure 8

With One Type of Disability Among Persons Ages 21-64 by Ethnicity in Hawaii, 2000 Census

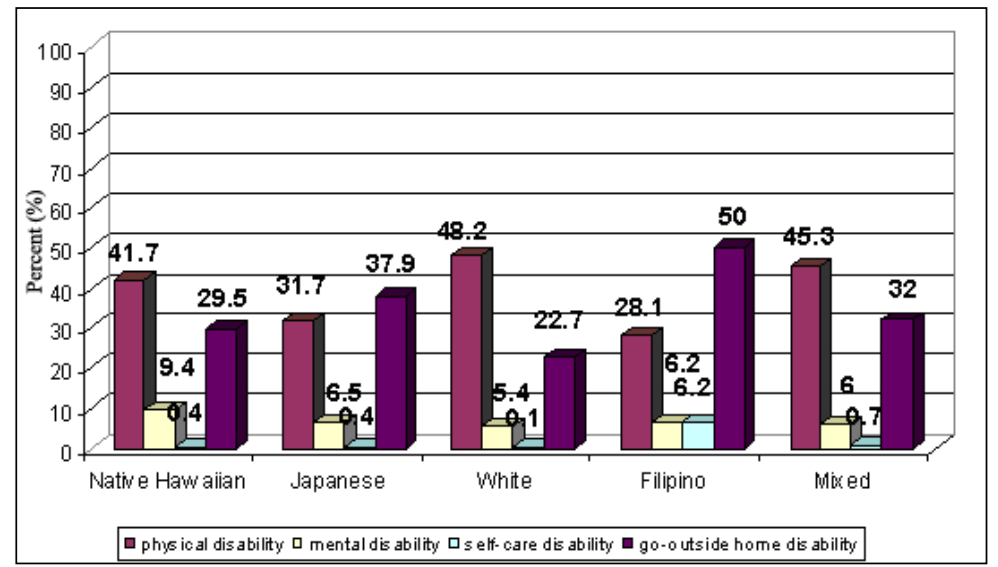

Figure 9

With One Type of Disability Among Persons Ages 65+ by Ethnicity in Hawaii, 2000 Census 


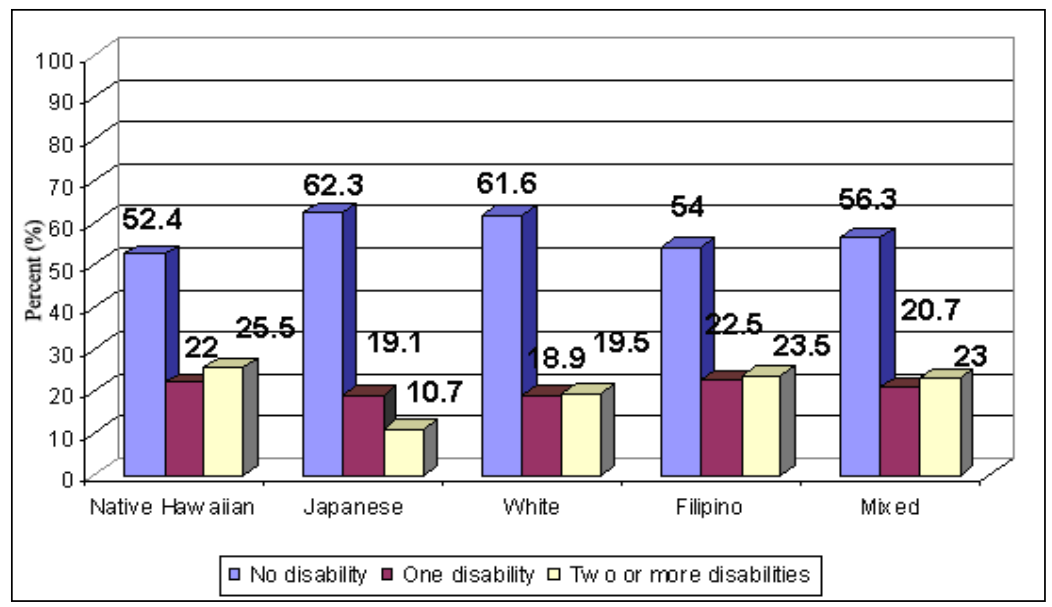

Figure 10

Persons Aged 65+ Years With No, One or Two Disabilities by Ethnicity in Hawaii, 2000 Census

\section{Hawaii BRFSS 2002}

The Behavioral Risk Factor Surveillance System (BRFSS) is an annual telephone survey of civilian, non-institutionalized adults ( $>18$ years) in the United States which has been conducted in all the states and territories since 1988. The BRFSS assesses risk factors for disease(s) and conditions related to the ten leading causes of death in the U.S. population. Findings from the Census and surveys like the BRFSS provide evidence that in general, throughout the U.S., disability is more common at older ages, among women, among those with lower incomes, lower education and the unemployed (CDC, 2003). In Hawaii, these patterns hold and disability is also more common on the neighboring islands than on Oahu. The BRFSS captures information on ethnicity through self-report. Native Hawaiian, Whites, Japanese and Filipinos make up the four major ethnic groups represented in the Hawaii BRFSS and are surveyed in sufficient numbers to allow for comparisons to made across these groups. Other ethnic groups representing smaller proportions of the population are not surveyed at sufficient levels to allow for comparisons across these groups. Thus, they are combined to form one ethnic group referred to as "others".

Since disability rates increase with age, a higher disability rate in one group than in another may simply reflect the different age structure (e.g., Japanese have a generally older population than
Native Hawaiians, in Hawaii). Statistical techniques were used to standardize the rates in the populations being compared, which eliminates the effects of different age distributions among different groups. Age adjusted prevalence rates are reported here for the BRFSS utilized age distribution \#22 for the working-age population (18-64 years) and age distribution \#18 for the elderly (65 and over) for the year 2000 projected U.S. population (Klein \& Schoenborn, 2001).

The BRFSS collects data on quality of life, including disability indicators such as activity limitations and use of special equipment. In general, BRFSS prevalence estimates for disability in Hawaii are lower than for those from US Census data. Self-reported activity limitations in Hawaii in 2002 ranged from 9$12 \%$ among all ethnic groups. This is much less than reported in mainland US states (for example, in Oregon, the range is from 19-23\% from 1996 to 1999) (Pobutsky, 2001). Another indicator of disability, the use of special equipment, ranged from $5-7 \%$ among ethnic groups in Hawaii, which is similar to other states in the US. Use of special equipment was highest among Japanese at $7.3 \%$, followed by Native Hawaiians at 6.8\%, Filipinos and other groups at $6.2 \%$ respectively and lowest for Whites at $4.8 \%$. 
Since disabilities are linked with age, data are presented by ethnicity and two age groups of interest: working aged (18-64 years) and elderly ( $>65$ years) adults. Disability can lead to employment problems for working aged adults, and for the elderly, disability is associated with additional health problems. Among working aged adults reporting activity limitations (Figure 11 ), the highest proportions were among Native Hawaiians (9.4\%), other groups $(8.7 \%)$ and Whites (8.5\%), and these percentages were not significantly different from each other. However, there was a statistically significant difference $(\mathrm{p}<.05)$ in the above mentioned prevalence rates compared to Filipinos (5.4\%) and Japanese (4.9\%) among working aged adults.

Among elderly adults, although the prevalence rate for activity limitations is highest among Native Hawaiians (30.9\%) and lowest among Japanese (19.6\%), the rate among Japanese but is significantly lower compared only to Whites (28.2\%) and others (31.2\%) ( $>$ >.05) and moderately lower when compared to Filipinos $(28.6 \%)(\mathrm{p}>.05$ but $<.10)$.

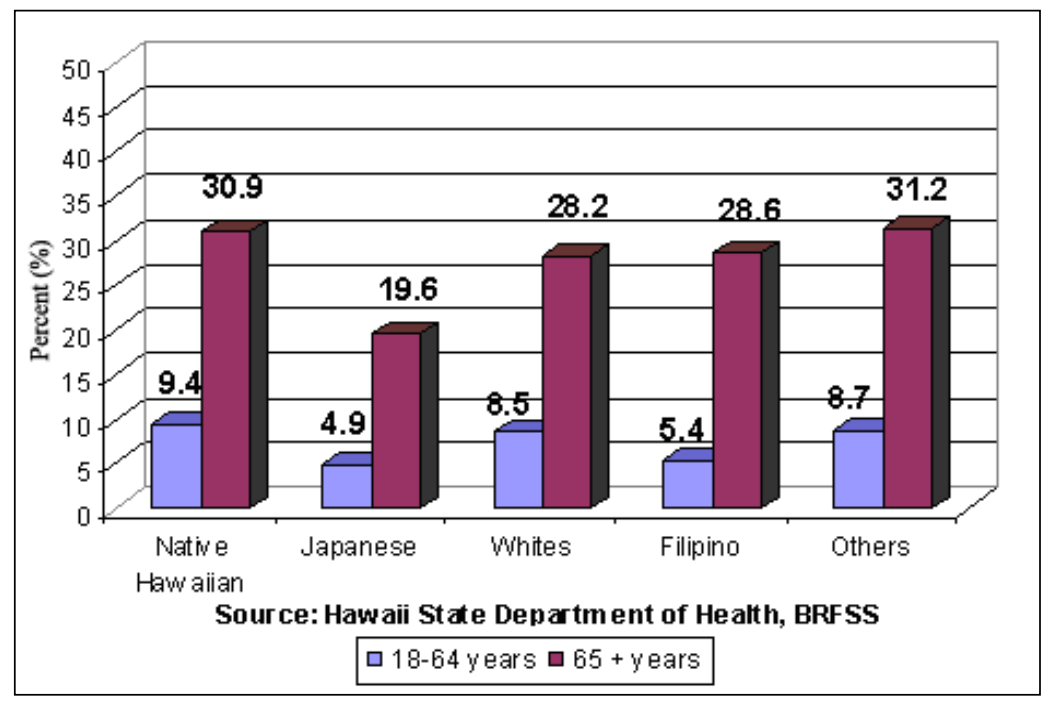

Figure 11

Activity Limitation by Ethnicity Among Working Age and Elderly Adults (age adjusted)

Similar to the findings for activity limitations, among working aged adults, Native Hawaiians are more likely to use special equipment because of health problems (4.2\%). The percentage of Hawaiians who use special equipment is significantly higher than for Whites (2.2\%) and Japanese $(1.5 \%) \quad(\mathrm{p}<.05)$. Although the percentage of Filipinos who use special equipment is similar to that of Whites $(2.2 \%$ vs. $2.1 \%$ ), it is moderately lower when compared to Hawaiians (2.1\% vs. $4.2 \%$ ), and moderately significant $(\mathrm{p}>.05$ but <.10). Working age Japanese are the least likely to use special equipment due to health problems $(1.7 \%)$, but the percentage is significantly lower when compared to other ethnic groups (3.7\%) and Hawaiians $(4.2 \%)(\mathrm{p}<.05)$.

Among elderly adults, use of special equipment was highest among Native Hawaiians (27.2\%), followed by Filipinos (26.6\%) and no statistically significant differences were found (see Figure 12).

In addition to the previously discussed definitions for disabilities, other measures of more severe disabilities are also included in the BRFSS. In addition to asking respondents if they have an activity limitation and/or uses special equipment, they are also asked whether 
they need help with their personal care (IADL), or routine needs (ADL). Instrumental activities of daily living (IADL) refers to needing help eating, bathing, dressing, or toileting, while activities of daily living (ADL) refers to needing help with routine tasks such as shopping or household chores.

Among working aged adults with disabilities (defined as those who have activity limitations or use special equipment)(Figure 13), other ethnic groups $(24.5 \%)$ and Native Hawaiians $(16.0 \%)$ reported the highest proportions needing help with their personal care, followed by Whites (11.1\%), and Japanese (5.8\%) with the lowest among Filipinos (4.2\%). The percentage of Filipinos requiring personal care assistance is significantly lower than that of Whites and the Hawaiians $(\mathrm{p}<.05)$.

Among elderly adults with disabilities (defined as those who have activity limitation or use special equipment)(Figure 13), those in the other ethnic group category had the highest proportion reporting needing help with their personal care $(44.3 \%)$, and this was significantly higher $(\mathrm{p}<.05)$ compared to Whites $(17.2 \%)$ and moderately higher $(\mathrm{p}>.05$ but $<.10)$ compared to Native Hawaiians (22.1\%). The proportion of Filipinos reporting needing help with their personal care (34\%) is the second highest, but only moderately higher $(\mathrm{p}>.05$ but <.10) compared to Whites (25.4\%).

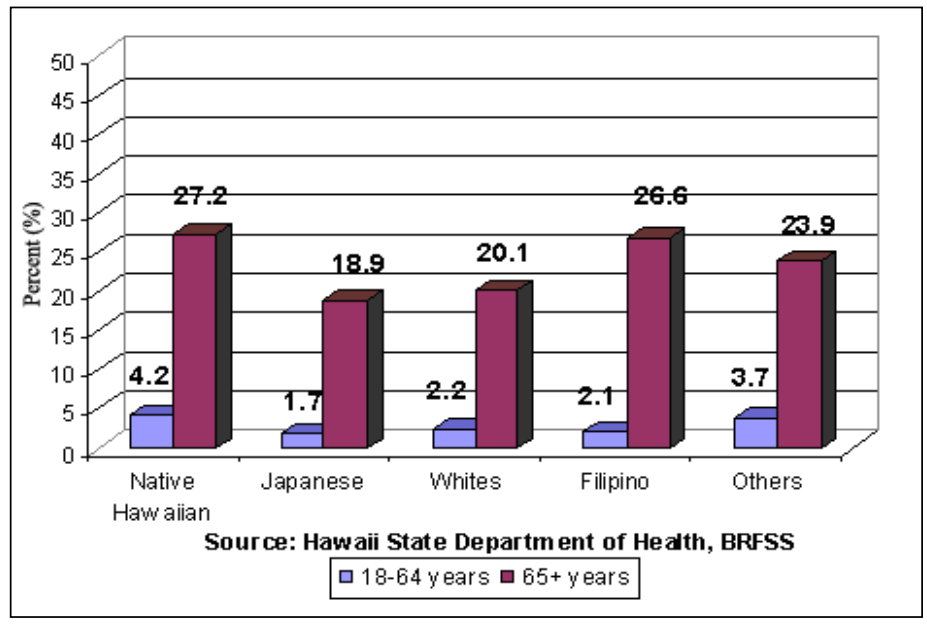

Figure 12

Use of Special Equipment by Ethnicity Among Working Age and Elderly Adults (age adjusted)

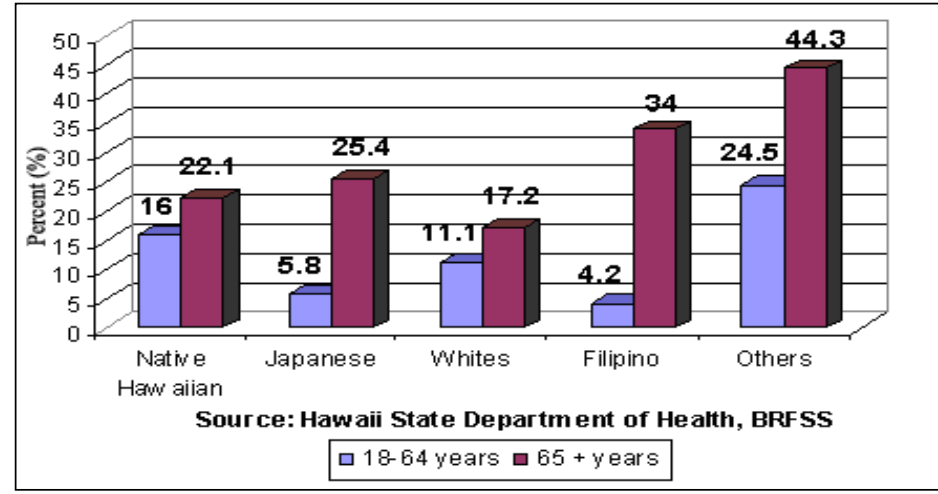

Figure 13

IADL Limitation (Requires Help With Personal Care Needs) by Ethnicity Among Working Aged and Elderly Adults (age adjusted) 
Among working aged adults with disabilities (defined as those who have activity limitations or use special equipment) (Figure 14), those reporting needing help with routine needs was highest among Native Hawaiians (44.9\%), followed by Japanese (30.4\%), other ethnic groups (28\%), Filipinos (25.9\%) and Whites (23.9\%). The higher proportion reported among Native Hawaiians was significantly higher $(\mathrm{p}<.05)$ compared to Whites $(23.9 \%)$ and moderately higher $(\mathrm{p}>.05$ but $<.10)$ compared to Filipinos and other ethnic groups.
Among elderly adults with disabilities (defined as those who have activity limitations or use special equipment) (Figure 14), those reporting needing help with routine help needs, Whites (39.4\%) has the lowest percentage needing help but this was only moderately lower ( $>.05$ but $<.10)$ compared to Native Hawaiians (59.2\%). The proportion of Native Hawaiians reporting needing help with routine needs was not statistically different from that of Filipinos, Japanese and other ethnic groups.

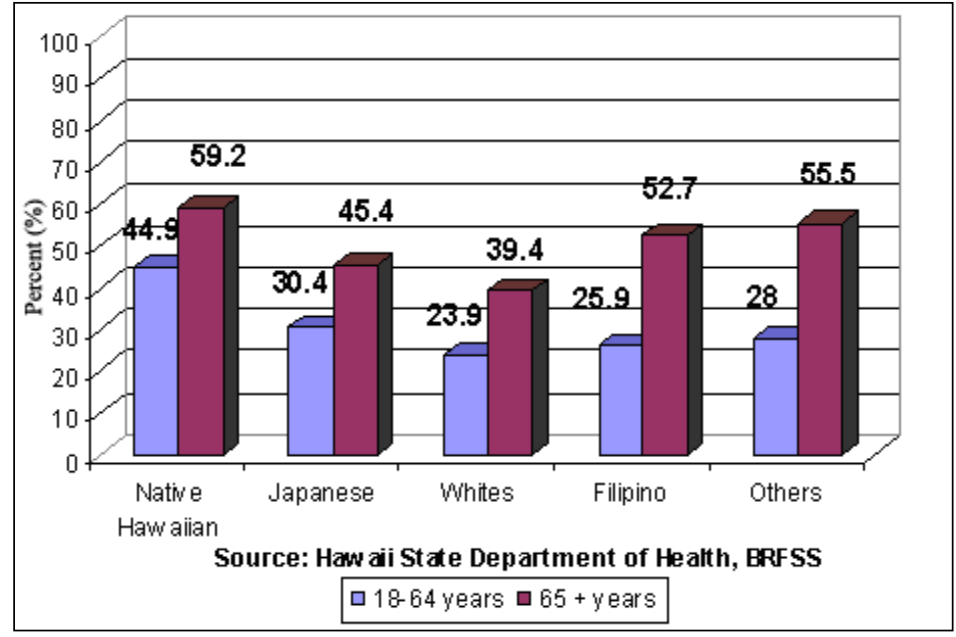

Figure 14

ADL Limitation (Requires Help With Routine Needs) by Ethnicity Among Working Aged and Elderly Adults (age adjusted)

Another proximate measure of disability included on the BRFSS is the reported length of time that a person was limited in activities. Activity limitations or use of special equipment for smaller lengths of time (e.g. less than one year), can be due to temporary conditions and/or injuries. More permanent disabilities or conditions are reflected among those who have lived with a disability for more than 10 years.

Among working aged adults with disabilities, fully $40.3 \%$ of Native Hawaiians reported living with a disability for more than ten years (Figure $15)$, followed by other ethnic groups (34.8\%), Whites (26.5\%), Japanese and Filipinos (12.1\%). The higher proportion among Native Hawaiians was significantly higher $(\mathrm{p}<.05)$ compared to Filipinos (12.1\%) and Japanese (16.6\%). The higher proportion among Whites was significantly higher $(\mathrm{p}<.05)$ compared to Filipinos (26.5\% vs. 12.1\%). Further, among other ethnic minorities, who reported the second highest proportion reporting living with a disability for more than 10 years, this was moderately higher $(\mathrm{P}>.05$ but $<.10)$ compared to Japanese (34.8\% vs. 16.6\%) and significantly higher $(\mathrm{P}<.05)$ compared to Filipinos $(34.8 \%$ vs. 12.1\%).

Among elderly adults, having a disability for more than ten years was highest among Native Hawaiians (77.4\%), followed by Filipinos 
(75.5\%), Japanese (57.6\%), Whites (46.1\%) and others (43\%). The lower proportion among Whites was significantly lower $(\mathrm{p}<.05)$ when compared to Filipinos and Native Hawaiians. The higher proportion reported among Native
Hawaiians percentage is significantly higher $(\mathrm{p}<.05)$ compared to other ethnic groups and is also moderately higher $(\mathrm{p}>.05$ but $<.10)$ when compared to Japanese.

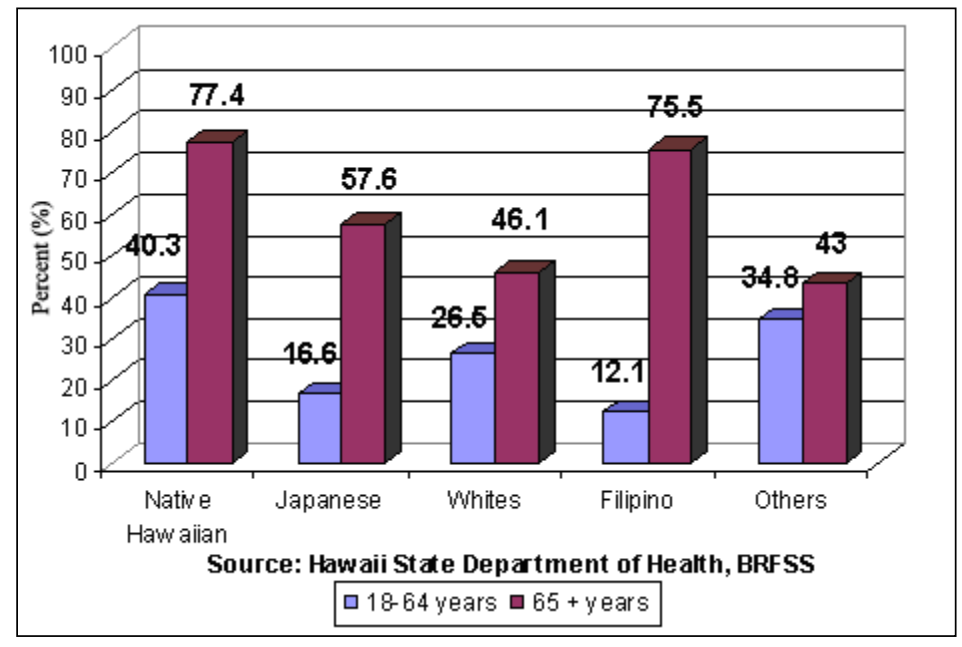

Figure 15

Activity Limitation for 10 or More Years by Ethnicity Among Working Aged and Elderly Adults (age adjusted)

For all of these indicators of more severe disabilities, Hawaii has higher rates; for example, in Oregon those reporting needing help with personal care did not exceed $10 \%$, while those reporting needing help with routine needs did not exceed 25\% in 1996, 1998 and 1999 (Pobutsky, 2001).

Self- reported conditions which caused activity limitations (and/or use of special equipment) differed by ethnicity as well. However, it is important to point out that the following proportions were not age-adjusted, due to the small sample size (after disaggregating the type of conditions causing limitations). Among Native Hawaiians with activity limitations, about one-third reported that stroke caused their disability. Other disabling conditions reported by Native Hawaiians included arthritis (14.8\%) walking problems (10.2\%), diabetes (9.8\%), back or neck problems (9.7\%) and lung/breathing problems (7.4\%). Among Japanese, one-third reported that arthritic conditions caused their disability (33.8\%), followed by heart problems (14.8\%), and eye/vision problems (9.9\%), and a wide range of other problems. Among Whites, the most common disabling conditions reported were arthritic conditions (21.4\%), followed by heart problems (12.7\%), fractures/bone or joint injuries (10.4\%) and back/neck problems (8.6\%), along with a wide range of other conditions. Among Filipinos, the majority reported heart problems (28.8\%) and arthritic conditions (25.5\%), followed by eye/vision problems (12.4\%) and lung/breathing problems (12.8\%). Among other groups, the majority reported heart problems (24.5\%), arthritic conditions (17.5\%) stroke (10.3\%) and walking problems (8.5\%) as the conditions causing their disability.

\section{Discussion}

In general, the 2000 US Census estimates of disability prevalence among Hawaii's major ethnic groups are higher when compared with 
the findings of the 2002 Hawaii BRFSS. This difference, in all likelihood, is due to the differing methodologies employed by the two survey systems. The US census is an interviewer-administered survey, performed house-to-house as opposed to the BRFSS, which is a phone survey of a random sample of the population under study. Furthermore, as previously discussed, the operational definition of disability is quite varied. The BRFSS and US Census do not use a congruent set of disability indicators, making it difficult to compare and contrast findings between the two populationbased surveillance systems. Despite these methodological and definitional issues, some general statements about the current state of disability in Hawaii can be made.

In general, among adults in the four major ethnic groups, Filipinos and Native Hawaiians report experiencing higher levels of disability than their Japanese and White counterparts. If we consider the use of special equipment, personal care needs, routine care needs, and length of time with a disability as indicators for disability severity (BRFSS), it appears that within the working-aged population, Native Hawaiians experience a more severe level of disability than other ethnic groups. Within the elderly population, it appears that Filipinos experience a more severe level of disability. What is most interesting is the fact that nearly one third of Native Hawaiians attribute their disability to the effects of a stroke, nearly one third of Filipinos attributed their disability to the effects of heart disease, as opposed to one fourth to one third of Whites and Japanese who attributed their disability to arthritis. An assumption here is that stroke and heart disease are more serious chronic conditions than arthritis, which may explain a significant portion of the variance regarding disability severity across these ethnic groups, as opposed to ethnicity itself.

\section{Conclusions}

We have described the current prevalence of disability among Hawaii's population based on two established population-based surveillance systems: The US Census and the Behavioral Risk Factor Surveillance System. Preliminary findings suggest that Native Hawaiians and Filipinos may be experiencing more severe levels of disability. The data also suggests that disability among Native Hawaiians and Filipinos may be associated with stroke and heart disease.

More information is needed about disability and health among ethnic groups in Hawaii and the Pacific region. Population aging in Hawaii, as well as the increase in non-communicable diseases will result in larger numbers of people with disabilities who will need health and other services. Further, more information is needed about the health-related quality of life and other quality of life indicators among people with disabilities in Hawaii, as well as information about the socio-economic status (income, education and occupation) among people with and without disabilities, as well as ethnicity.

Increasing the capacity for surveillance of disability can facilitate development of policy and project service needs for people with disabilities. Other measures used to examine disability might need to be employed in future investigations. For example, DALY's (disability adjusted life years) (Murray \& Lopez, 1996), measures "incident lost years of healthy life" and is an example of improved methods for estimated disability. This is calculated as the sum of the years of life lost due to premature mortality in the population (YLL) and the years lived with a disability (YLD) (incident cases or a particular disease or condition). Such measures would be important, particularly for vulnerable minority populations such as Native Hawaiians and Filipinos.

\section{References}

Bickenbach, J. E., Charrerji, S., Badley, E. M., and Ustun, T. B. (1999). Models of disablement, universalism and the international classification of impairments, disabilities and handicaps. Social Science \& Medicine, 48, 1173-1187.

Center for an Accessible Society. (2003). Research definitions of disability from NIDRR. Retrieved May 21, 2002, from http://www.accessiblesociety.org/topics/demographics-identity/nidrr-lrp-defs.htm 
Center for an Accessible Society. (2003). Disability and the 2000 census: What reporters need to know. Retrieved May 21, 2002, from http://www.accessiblesociety.org/topics/demographicsidentity/nidrr-lrp-defs.htm

Centers for Disease Control and Prevention. (1993). Use of race and ethnicity in public health surveillance: Summary of the CDC/ATSDR workshop. Morbidity and Mortality Weekly Report, 42 (No. RR-10).

Centers For Disease Control and Prevention. (1994). Quality of life as a new public health measure Behavioral Risk Factor Surveillance System, 1993. Morbidity and Mortality Weekly Report, 43(20).

Centers for Disease Control and Prevention. (1997). Prevalence of disabilities and associated health conditions among adults--United States, 1999. Morbidity and Mortality Weekly Report, February 23, 2001, 5(7), 120-125.

Centers for Disease Control and Prevention. (1998). Chronic diseases and their risk factors: The nation's leading causes of death. Atlanta, GA: Author.

Centers for Disease Control and Prevention. (2000). State-specific prevalence of disability among adults11 States and the District of Columbia, 1998. Morbidity and Mortality Weekly Report, 49(31), 711-714.

Centers for Disease Control and Prevention. (2002). Health disparities among Native Hawaiians and other Pacific Islanders garner little attention. Chronic Disease Notes and Reports, 15(2). Retrieved April 29, 2003, from http://www.cdc.gov/nccdphp/cdnr/cdnr_spring0205.htm

Centers for Disease Control and Prevention and NIDRR. (2002). Disability and secondary conditions, focus area 6, reports and proceedings. Atlanta, GA: Author.

Centers for Disease Control and Prevention. (2003). Summary health statistics for the US population: National health interview survey, 2000. Atlanta, GA: DHHS-CDC-NCHS, Series 10, No. 214 (Tables 3-7).

Centers for Disease Control and Prevention. (CDC). Behavioral Risk Factor Surveillance System Survey Data. Atlanta, GA: Author.

Dunlop, D. D., Hughes, S. L., and Manheim, L. M. (1997). Disability in activities of daily living: patterns of change and a hierarchy of disability. American Journal of Public Health, 87, 3.

Ellis, E. (1997). The demographics of disability in people with disabilities. New Jersey: The New Jersey Developmental Disabilities Council, 10-12.

Evans, R. G., Barer, M. L., and Marmor, T. R. (Eds) (1994). Why are some people healthy and others not? The determinants of health of populations. New York: Aldine de Gruyter.

Goebert, D. and Birnie, K. K. (1998). Injury and disability among Native Hawai'ans. Pacific Health Dialog, 5(2), 253-265.

Hawaii State Department of Health. (2002). Behavioral risk factor surveillance survey (on-going). Retreived August 29, 2003, from http://www.state.hi.us/doh/stats/surveys/brfss.html

Hawaii State Department of Health. (2001). The State of Hawaii arthritis report: What the 2000 BRFSS shows. Retrieved August 20, 2003, from http://www.state.hi.us/doh/stats/surveys/2000/arthritis2000.pdf

Kaplan, D. (2003). The definition of disability. Retrieved May 20, 2003, from http://www.accessiblesociety.org/topics/demographics-identity/nidrr-lrp-defs.htm

Kaye, H. S. (1997). Disability watch: The status of people with disabilities in the United States. Oakland, CA: Disability Rights Advocates, 35.

Kaye, H. S. (2003) Quoted in Disability and the 2000 Census: What reporters need to know. http://www.accessiblesociety.org/topics/demographics-identity/census2000.htm

Kekuni Blaisdell, R. (1993). The health status of Kanaka Maoli (Indigenous Hawaiians). Asian Pacific Islander American Journal of Health, 1(2), 117-160.

Klein, R. J., and Schoenborn, C.A. (2001). Age adjustment using the 2000 projected population. Healthy people 2010 statistical notes. Atlanta, GA: Centers for Disease Control and Prevention. 
Kraus, L. E., Stoddard, S., and Gilmartin, D. (1996). Chartbook on disability in the United States: 1996. Berkeley, CA: InfoUse.

LaPlante, M. (1993). State estimates of disability in America. Washington, DC: National Institute on Disability and Rehabilitation Research, USDE-OSERS.

LaPlante, M. P., and Carlson, D. (1996). Disability statistics report: Disability in the United Statesprevalence and causes, 1992. Washington, DC: National Institute on Disability and Rehabilitation Research, USDE-OSERS.

LaPlante, M. (2003) Qquoted in Disability and the 2000 Census: What reporters need to know. Retrieved May 20, 2003, from http://www.accessiblesociety.org/topics/demographicsidentity/census2000.htm

Lollar, D. (2002). Public health and disability: Emerging opportunities. Public Health Reports, 117(2), 131-137.

Lollar, D. (2003) Quoted in Disability and the 2000 Census: What reporters need to know. Retreived May 20, 2003, from http://www.accessiblesociety.org/topics/demographics-identity/census2000.htm

McGinnis, M. J., and Foege, W. H. (1993). Actual causes of death in the United States. The Journal of the American Medical Association, 270, 2207-2212.

McNeil, J. (1993). Americans with disabilities: 1991-1992-data from the survey of income and program participation. Washington, DC: U.S. Department of Commerce, Bureau of the Census: Current Population Reports.

McNeil, J. (1997). Disability. Washington, DC: U.S. Department of Commerce, Bureau of the Census.

Murray, C. J., and Lopez, A. D. (Eds) (1998). The global burden of disease: A comprehensive assessment of mortality and disability from diseases, injuries, and risk factors in 1990 and projected to 2020. Cambridge, MA: The Harvard School of Public Health on behalf of the World Health Organization and the World Bank.

Pobutsky Workman, A., \& Kamminga Quinata, D. (1996). Epidemiology as labeling: neurological diseases and stigma on the island of Guam. ISLA: A Journal of Micronesian Studies, 4(1), 47-69.

Pobutsky, A. M. (2001). BRFSS data update: Disability prevalence estimates for 1996, 1998 and 1999. Disability and Health Quarterly Newsletter, 2, 1. Retrieved September 26, 2003, from http://cdrc.ohsu.edu/oodh/BRFSSUpdateWin01.php?menuitem=BRFSSDataandStatistics

Pope, A. M., and Tarlov, A. R. (Eds.) (1991). Disability in America: Toward a national agenda for prevention. Washington, DC: National Academy Press.

Robello Breitha, O. (1991). Olivia - My life of exile in Kalaupapa. Honolulu, HI: Arizona Memorial Museum Association.

Stoddard, S., Jans, L., Ripple, J., and Kraus, L. (1998). Chartbook on disability in the United States. Washington, DC: National Institute on Disability and Rehabilitation Research.

US Department of Commerce, Bureau of the Census. (1989). Population profile of disability (Task I). Washington, D.C: Author.

US Department of Commerce, Bureau of the Census. (1990). Labor force profile of persons with disabilities (Task IV). Washington, DC: Author.

US Department of Commerce, Bureau of the Census. (1997). Aging in the United States: Past, present and future. Washington, DC: Author.

U.S. Department of Commerce, Bureau of the Census. (1997). Disabilities affect one-fifth of all Americans. Census Brief, CENBR/97-5. Washington, DC: Author.

U.S. Department of Commerce, Bureau of the Census. (2001). Americans with disabilities: Household economic studies, 1997. Current Population Reports, P7-73. Washington, DC: Author.

World Health Organization. (1999). International classification of impairments, disabilities, and handicaps beta-2 draft. Geneva: Author.

Zola, I. K. (1993). Disability statistics, what we count and what it tells us: A personal and political analysis. Journal of Disability Policy Studies, 4 (2). 


\author{
Author Information \\ Ann M. Pobutsky, PhD, Chronic Disease Epidemiologist \\ Hawaii State Department of Health \\ Community Health Division \\ 1250 Punchbowl St., Rm. 227 \\ Honolulu, Hawaii 96813 \\ Ph: 808-586-4485 \\ E-Mail: agpobutsk@mail.health.state.hi.us \\ Robert Hirokawa, MPH, Epidemiologist \\ Hawaii State Department of Health \\ Chronic Disease Management and Control Branch \\ 601 Kamokila Blvd., Room 344 \\ Kapolei, Hawaii 96707 \\ Ph: 808-692-7461 \\ Email: rghiroka@mail.health.state.hi.us \\ Florentina Reyes-Salvail, MS, Research Statistician \\ Hawaii State Department of Health \\ Community Health Division \\ 1250 Punchbowl St., Rm. 262 \\ Honolulu, Hawaii 96813 \\ Ph: 808-586-4509 \\ Email: brfsshi@mail.health.state.hi.us
}

